\title{
In vitro Screening of Cassava (Manihot Esculenta Crantz) Varieties to Drought and Phosphorus Stresses
}

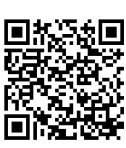

\author{
Opeyemi M Adejoju and Jelili T Opabode* \\ Department of Crop Production and Protection, Obafemi Awolowo University, Nigeria
}

Submission: August 15, 2018, Published: September 04, 2018

"Corresponding author: Jelili T Opabode, Department of Crop Production and Protection, Obafemi Awolowo University, Ile- Ife, Nigeria; Tel: 8034172865; Email: jopabode@gmail.com

\begin{abstract}
Rapid selection of drought and phosphorus (P) deficit tolerant cassava varieties by in vitro screening is essential for sustainable food production. The objectives of this study were to describe the morphological response of eight cassava cultivars to in vitro mannitol-induced drought and P stress and identify tolerant ones. Plantlets were raised from nodal segments on three stress media: control, moderate and extreme water and P stress. The study was a 3 x 8 factorial arrangement in completely randomized design with three replicates. All cultivars developed shoots, roots, leaves and apical meristem from nodal segment explants in control medium while $25 \%$ of the cultivars developed those organs on moderate water and P stress (MS) medium. Cultivar TME 419 developed roots, shoots, leaves and apical meristem in extreme water and P stress (ES) medium; whereas MS-8 did not produce those organs two weeks after grown on the ES medium. The ES medium reduced number of leaves by $50 \%$ in TME 419 and TMS $97 / 2205$, by greater than 50\% in UMUCASS 36, UMUCASS 37, UMUCASS 38 and TMS 4(2) 1425, and 100\% in TMS 98/0581 and MS-3. Cultivars UMUCASS 36, UMUCASS 37, UMUCASS 38, TMS 98/0581, MS-8, TMS 4(2) 1425 did not develop root on MS and ES media. TME 419 developed roots on ES whereas TMS 97/2205 roots failed to elongate. The study concluded that TME 419 is tolerant of drought and P deficit stresses and strongly recommended for farmers.
\end{abstract}

Keywords: Growth; Moisture deficit; Phosphorus deficiency; Root crop; Tolerance

Abbreviations: P: Phosphorus; NL: Number of Leaves Per Plantlet; NR: Number of Roots Per Explant; NS: Number of Shoot; NCHL: Number of Chlorotic Leaves Per Plantlet; SL: Shoot Length; RL: Root Length

\section{Introduction}

Cassava is an important cash and food crop of resourcelimited farmers in Africa, Asia, Latin America and Caribbean [1]. Cassava produces more carbohydrates per hectare than the main cereal crops (such as maize, rice and wheat) and it can be cultivated with considerable lower cost [1]. About $70 \%$ of global cassava root production is consumed by human in various forms (processed and unprocessed) while the remaining quantity is utilized for animal feed and industrial products such as starch, glucose, alcohol [2,3]. Furthermore, cassava young leaves are consumed as a vegetable in many African countries to provide protein, calcium, iron and vitamins [2]. As a result, cassava has great potentials for attainment of food security and alleviation of poverty in developing countries.

Water deficit or drought stress is becoming a major limitation to cassava production. This is because global monitoring and analysis of climatic variables have provided evidence that the countries where cassava is cultivated are experiencing impacts of climate change [4]. Though cassava is tolerant of drought stress to some extent, studies have confirmed that cassava is susceptible

to drought stress at establishment stage; i.e, from sprouting to 4 month old [5,6]. Exposure of cassava young plants to drought stress has a long term negative impacts on growth and physiological processes, depending on length and intensity of drought, at later stage of growth even if the drought stress is removed [6]. Drought stress during establishment stage of cassava plants significantly reduces the growth and development of both the primary roots and shoots [7]. Furthermore, tuber formation is difficult under water-deficit conditions, which delays harvesting [5,7] A study has shown that drought stress caused $45 \%$ reduction in leaf formation, which resulted in $83 \%$ and $97.8 \%$ reduction in tuber yield and starch content, respectively [8]. Similarly, nitrogenuse efficiency of cassava experiencing drought is decreased as a result of the partitioning of higher proportion of nitrogen to root biomass than to shoot biomass [6]. Vandegeer et al. [8], reported that cyanide content increased three-fold in young leaves and four-fold in tubers of water-stressed cassava plants.

In addition to water deficit, Phosphorus deficiency is becoming a major limitation of cassava production in many infertile acid soils such as Ultisols, Alfisols, Oxisols and Inceptisols [9]. Phosphorus 
availability becomes a main problem in highly weathered tropical soils of most cassava growing regions because such soils have a significant capacity to sorb large amounts of phosphorus, taking them out of the soil solution. This limits the availability of inorganic phosphorus for plants, whether it is already contained in the soil or added as fertilizer. Phosphorus stimulates plant processes such as energy transfer reactions, development of reproductive structures, crop maturity, root growth and protein synthesis [9,10]. Phosphorus-deficient cassava plants are generally short and spindly with thin stems, small and narrow leaves and short petioles. The leaves are generally dark green while one or two lower leaves may be dark yellow to orange and in some varieties purplish with necrotic white spots. In cassava, at severe phosphorus limitation, the rate of photosynthesis is depressed, as indicated by the decrease in starch accumulation [11]. The sufficiency range of $P$ in young fully expanded leaf blades is $0.38-0.50 \%$ P. However, the critical level of $\mathrm{P}$ in soil is $4-6 \mu \mathrm{g} / \mathrm{g}$ Bray-II extractable P. To control P def1ciency, 25-50kg P/ha such as single or triple superphosphate or compound fertilizers, which are expensive. Thus, combine drought and P deficiency aggravate the problems of cassava production in developing countries of Africa, Asia and Latin America.

Rapid selection of drought and Phosphorus-deficiency tolerant cassava varieties by in vitro screening is essential for sustainable production of cassava in developing countries. Compare with conventional breeding, in vitro screening has the potential to significantly reduce selection and breeding cycle.
However, response of cassava explants to drought stress and $\mathrm{P}$ starvation in culture medium is not known. Formation of organs by different explants grown on culture medium subjected to combine drought and P stresses has not been described. We hypothesized that cassava nodal segment explants would form organs, grow and respond to water and $\mathrm{P}$ stresses in vitro for identification of tolerant varieties. The objectives of this study were to describe the morphological response of eight cassava cultivars to in vitro drought and phosphorus stresses and identify tolerant ones.

\section{Materials and Methods}

\section{Plant materials and conditions of source of explants}

Healthy plants were raised from stem-cuttings of eight cassava cultivars, viz, UMUCASS 36, UMUCASS 37, UMUCASS 38, TMS 97/2205, MS-3, TMS 4(2) 1425, TME 419 and TMS 98/0581, at the greenhouse facility of NACGRAB, Ibadan. Stem-cuttings $(10 \mathrm{~cm}$ long) were planted horizontally in plastic pot $(19 \mathrm{~cm} \mathrm{x} 21 \mathrm{~cm} \mathrm{x}$ $13 \mathrm{~cm}$ ) containing $4 \mathrm{~kg}$ loamy soil with these soil properties:
a. $\mathrm{pH}=7.2$
b. Organic carbon $=4.3 \%$
c. $\quad$ Total nitrogen $=5.1 \%$
d. Cation exchange capacity $=15.3 \mathrm{cmolkg}^{-1}$

Each plant was irrigated manually, and daily with $800 \mathrm{~mL}$ tap water, pH 6.8.

\section{Culture composition, growth conditions, stress treatment and experimental design}

Table 1: Composition of the three culture media used for the study.

\begin{tabular}{|c|c|c|c|}
\hline Nutrient Compound & CT (g/l) & MS (g/l) & $\mathrm{ES}(\mathrm{g} / \mathrm{l})$ \\
\hline $\mathrm{NH}_{4} \mathrm{NO}_{3}$ & 1.65 & 1.65 & 1.65 \\
\hline $\mathrm{KNO}_{3}$ & 1.9 & 2.85 & 3.8 \\
\hline $\mathrm{CaCl}_{2} \cdot 2 \mathrm{H}_{2} \mathrm{O}$ & 0.44 & 0.44 & 0.44 \\
\hline $\mathrm{MgSO}_{4} \cdot 7 \mathrm{H}_{2} \mathrm{O}$ & 0.37 & 0.37 & 0.37 \\
\hline $\mathrm{KH}_{2} \mathrm{PO}_{4}$ & 0.17 & 0.085 & - \\
\hline $\mathrm{NaHPO}_{4}$ & 0.147 & 0.074 & - \\
\hline $\mathrm{H}_{3} \mathrm{BO}_{4}$ & $6.2 \times 10^{-3}$ & $6.2 \times 10^{-3}$ & $6.2 \times 10^{-3}$ \\
\hline $\mathrm{MnSO}_{4} \cdot 4 \mathrm{H}_{2} \mathrm{O}$ & $2.23 \times 10^{-2}$ & $2.23 \times 10^{-2}$ & $2.23 \times 10^{-2}$ \\
\hline $\mathrm{ZnSO}_{4} \cdot \mathrm{H}_{2} \mathrm{O}$ & $8.6 \times 10^{-3}$ & $8.6 \times 10^{-3}$ & $8.6 \times 10^{-3}$ \\
\hline $\mathrm{Kl}$ & $8.3 \times 10^{-5}$ & $8.3 \times 10^{-5}$ & $8.3 \times 10^{-5}$ \\
\hline $\mathrm{NaMO}_{4} \cdot 2 \mathrm{H}_{2} \mathrm{O}$ & $2.5 \times 10^{-4}$ & $7.4 \times 10^{-2}$ & $1.5 \times 10^{-1}$ \\
\hline $\mathrm{CuSO}_{4} \cdot 5 \mathrm{H}_{2} \mathrm{O}$ & $2.5 \times 10^{-4}$ & $2.5 \times 10^{-4}$ & $2.5 \times 10^{-4}$ \\
\hline $\mathrm{CoCl}_{2} \cdot 6 \mathrm{H}_{2} \mathrm{O}$ & $2.5 \times 10^{-4}$ & $2.5 \times 10^{-4}$ & $2.5 \times 10^{-4}$ \\
\hline $\mathrm{FeSO}_{4} .7 \mathrm{H}_{2} \mathrm{O}$ & $2.78 \times 10^{-2}$ & $2.78 \times 10^{-2}$ & $2.78 \times 10^{-2}$ \\
\hline $\mathrm{Na}_{2}$ EDTA. $2 \mathrm{H}_{2} \mathrm{O}$ & $3.36 \times 10^{-2}$ & $3.36 \times 10^{-2}$ & $3.36 \times 10^{-2}$ \\
\hline Myo-Inositol & 10 & 10 & 10 \\
\hline Nicotinic Acid & $5.0 \times 10^{-5}$ & $5.0 \times 10^{-5}$ & $5.0 \times 10^{-5}$ \\
\hline Pyridoxine $\mathrm{HCl}$ & $5.0 \times 10^{-5}$ & $5.0 \times 10^{-5}$ & $5.0 \times 10^{-5}$ \\
\hline Thyamine & $1.0 \times 10^{-5}$ & $1.0 \times 10^{-5}$ & $1.0 \times 10^{-5}$ \\
\hline
\end{tabular}




\section{Agricultural Research \& Technology: Open Access Journal}

\begin{tabular}{|c|c|c|c|}
\hline Glycine & $2.0 \times 10^{-4}$ & $2.0 \times 10^{-4}$ & $2.0 \times 10^{-5}$ \\
\hline Sugar & 30 & 30 & 30 \\
\hline NAA (Naphthalene acetic acid) & $1.0 \times 10^{-5}$ & $1.0 \times 10^{-5}$ & $1.0 \times 10^{-5}$ \\
\hline BAP (Benzylaminopurine) & $5.0 \times 10^{-5}$ & $5.0 \times 10^{-5}$ & $5.0 \times 10^{-5}$ \\
\hline Purified Agar & 7 & 7 & 7 \\
\hline Mannitol & - & $10.00(-593.0 \mathrm{KPa})$ & $20.00(-740 \mathrm{KPa})$ \\
\hline $\mathrm{pH}$ & $5.7 \pm 0.10$ & $5.7 \pm 0.10$ & $5.7 \pm 0.10$ \\
\hline
\end{tabular}

${ }^{a}$ According to Murashige \& Skoog [12] with modifications CT= control (unstress) medium; MS= moderate water and P stress medium; ES= extreme water and P stress medium.

Three culture media were used in the study: Control (unstress), moderate waeter and P stress and extreme water and P stress. Control medium contained Murashige \& Skoog [12] mineral salt and vitamins supplemented with $30 \mathrm{~g} / \mathrm{L}$ sucrose and $7 \mathrm{~g} / \mathrm{L}$ agar. Moderate water and P stress medium contained MS mineral salts and vitamins (devoid of 50\% P) supplemented with 30g/L sucrose, $7 \mathrm{~g} / \mathrm{L}$ agar and $10 \mathrm{~g} / \mathrm{L}$ mannitol. Extreme water and $\mathrm{P}$ stress medium contained MS mineral salts and vitamins (devoid of P) supplemented with 30g/L sucrose, $7 \mathrm{~g} / \mathrm{L}$ agar and $20 \mathrm{~g} / \mathrm{L}$ mannitol. Mannitol provided water stress in vitro. Detail composition of the three culture media is presented in Table 1 . The $\mathrm{pH}$ of the medium was adjusted to 5.8 by $\mathrm{HCl}(1 \mathrm{~N})$ or $\mathrm{NaOH}(1 \mathrm{~N})$ prior to autoclaving at $121{ }^{\circ} \mathrm{C}$ for $15 \mathrm{~min}$ at $1.05 \mathrm{kgcm}^{-2}$ pressure. Growth regulators were filter-sterilized through $0.22 \mu \mathrm{M}$ Millipore filters and added to media after autoclaving. Cultures were maintained under $16 \mathrm{~h}$ photoperiod, with $20 \mu \mathrm{mol} \mathrm{m}^{-2} \mathrm{~s}^{-1}$ light intensity provided by coolwhite fluorescent tubes at $25 \pm 2{ }^{\circ} \mathrm{C}$.

Plantlets of the eight cassava cultivars were raised from surfaced sterilized nodal segment $(5 \mathrm{~cm}$ long) explants obtained from one-month old plants on the three culture media. The study

\section{Results and Discussion}

Table 2: Formation of organs by cassava nodal segment in vitro grown three stress media at 2 weeks after culture initiation.

\begin{tabular}{|c|c|c|c|c|c|c|c|c|c|c|c|c|}
\hline \multirow[t]{2}{*}{ Cultivar } & \multicolumn{3}{|c|}{ Apical Meristem } & \multicolumn{3}{|c|}{ Elongated Stem } & \multicolumn{3}{|c|}{ Elongated Root } & \multicolumn{3}{|c|}{ Young Leaves } \\
\hline & CT & MS & ES & CT & MS & ES & CT & MS & ES & CT & MS & ES \\
\hline UMUCASS 36 & + & + & + & + & + & + & + & - & - & + & + & + \\
\hline UMUCASS 37 & + & - & - & + & + & + & + & - & - & + & + & + \\
\hline UMUCASS 38 & + & + & - & + & + & + & + & - & - & + & + & + \\
\hline TMS 98/0581 & + & + & + & + & + & + & + & + & - & + & + & + \\
\hline TME 419 & + & + & + & + & + & + & + & + & + & + & + & + \\
\hline MS-3 & + & + & - & + & + & - & + & - & - & + & + & - \\
\hline TMS 4(2)1425 & + & + & + & + & + & + & + & - & - & + & + & + \\
\hline TMS 97/2205 & + & - & + & + & + & + & + & - & - & + & + & + \\
\hline
\end{tabular}

+: present; -: absent

TMS: Tropical Manihot species; TME: Tropical Manihot esculenta; CT: Control; MS: Moderate Stress; ES: Extreme Stress.

Status of organ development by nodal segment explants grown in the three media at two weeks of culture initiation is presented at Table 2. All nodal segment explants survived in the three cultures media. Developing organs had become visible on responding explants in all cultivars as from one week after culture establishment. Explants of all cultivars grown on CT medium developed apical meristem. However, only two (UMUCASS 37 and was $3 \times 8$ factorial arrangement in completely randomized design with three replicates. Fifteen explants constituted a replicate. Cultures were kept in a growth chamber at $25 \pm 2{ }^{\circ} \mathrm{C}$ and 16 -hour photoperiod (irradiation $=90 \mu \mathrm{mol} \mathrm{m}^{-2} \mathrm{~s}^{-1}$ ). A week after culture initiation, observations were made on survival of explants. Presence or absence of elongated stem, elongated root, young leaves, expanded leaves and axillary buds on the explants were recorded at six weeks after culture initiation. Data were obtained on number of leaves per plantlet (NL), number of roots per explant (NR), number of shoot (NS), number of chlorotic leaves per plantlet (NCHL), shoot length (SL) and root length (RL) at 12 weeks.

\section{Statistical analysis}

Data obtained from tagged, five randomly selected plantlets averaged per replication were used for analysis of variance. Count data, not being normally distributed, were subjected to squareroot transformation. The transformed data were subjected to analysis of variance using PROC GLM of the Statistical Analysis Systems [13]. Means were separated by Tukey's test at $5 \%$ level of probability. 
MS and ES media, respectively. There were presence of young leaves in all cultivars on CT and MS media but only MS-3 did not develop young leaves on ES medium. Nodal segment is the most suitable explant for cassava in vitro propagation [14], hence it was explant of choice for this study. In normal cassava propagation culture medium, nodal segment produces shoots and roots in one week of culture initiation, depending on cultivars and medium composition [14]. In the present work, nodal segment explant of all cultivars grown on CT medium produced shoot and root at two weeks indicating suitable medium composition and environment for explants growth. However, the situation was not the same with explants grown on MS and ES media, which is a manifestation of the cultivars response to the mannitol-induced drought and $P$ deficiency stresses. Clearly, our results indicated cultivar difference in organ development under in vitro drought and $\mathrm{P}$ stresses. Although, cassava response to combine in vitro drought and P stresses has not been reported, Jolayemi and Opabode [15], have reported differential varietal response in cassava to manntol-

Table 3: Mean squares from analysis of variance of some in vitro growth parameters of cassava plantlets obtained from nodal segment as influenced by water and phosphorus stresses.

\begin{tabular}{|c|c|c|c|c|c|c|c|}
\hline SV & DF & NL & NR & NCHL & NS & SL & RL \\
\hline Rep & 2 & 0.44 & 0.11 & 0.14 & 0 & 2.91 & 1.32 \\
\hline Stress (S) & 2 & $1.13^{* *}$ & $0.17^{* *}$ & $0.06 \mathrm{NS}$ & $0.03 \mathrm{NS}$ & $3.39^{* *}$ & $0.84 \mathrm{NS}$ \\
\hline Cultivar (C) & 7 & $0.42^{* *}$ & $0.33^{* *}$ & $0.17 \mathrm{NS}$ & $0.06 \mathrm{NS}$ & $1.60^{* *}$ & $1.86 \mathrm{NS}$ \\
\hline SX C & 14 & $0.71^{* *}$ & $0.14^{* *}$ & $0.16 \mathrm{NS}$ & $0.07 \mathrm{NS}$ & $1.44^{* *}$ & $0.93 \mathrm{NS}$ \\
\hline Error & 46 & 0.08 & 0.07 & 0.06 & 0 & 0.39 & 0.65 \\
\hline $\mathrm{R}^{2}(\%)$ & & 81 & 59 & 69 & 100 & 71 & 50 \\
\hline
\end{tabular}

*: Level of significance at $\mathrm{P} \leq 0.05$; ${ }^{* *}$ : Level of significance at $\mathrm{P} \leq 0.01$; ns: not significant; R-sq: R-square value; SV: Source of variation; DF: Degree of freedom; NL: Number of leaves; NR: Number of root; NCHL: Number of chlorotic leaves; NS: Number of shoot; SL: Shoot length; RL: Root length.

Results of analysis of variance of growth parameters are presented in Table 3. Stress medium and cultivar had significant effects on NL, SL and NS. However, stress medium and cultivar had no significant effects on NS, RL and NCHL. Also, interaction induced drought stress. It is noteworthy that TME 419 developed all organs examined in ES medium, including root, the most difficult organ to develop by cassava in vitro. This suggests that TME 419 is tolerant of drought and P stresses. Recently, TME 419 has been reported to display vigorous growth under mannitolinduced drought stress, suggesting high productivity potential under water deficit conditions. Cultivar TME 419 is one of farmerpreferred cassava cultivars in West Africa because of its fast growth rate, and ability to suppress weeds and produce high tuber yield under poor agronomic management [16]. On the other hand, MS-3 failed to develop any organs in ES medium, suggesting the cultivar is sensitive to drought and P stresses. Most importantly, our data established that nodal segment explants grown in culture medium containing mannitol as drought-inducing agent and devoid of P developed organs in response to imposed stresses. A situation that make in vitro selection of drought and P deficiency tolerant one feasible. of stress medium and cultivar were significant on NL, NR and SL. Therefore, interactions means were used to examine the influence of stress medium on each cultivar for NL, NR and SL as presented in Figure 1.

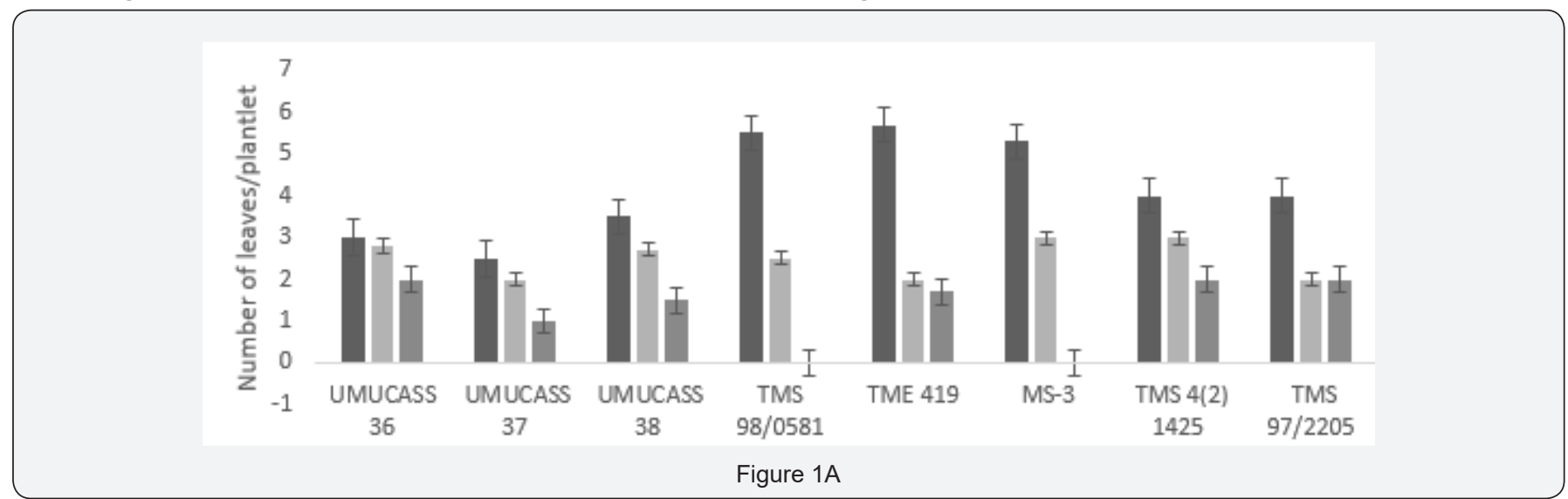

Compare with control medium, MS reduced number of leaves by an average of $17 \%$ and ES reduced number of leaves by $50 \%$ in UMUCASS 36, UMUCASS 37, UMUCASS 38 and TMS 4(2) 1425 (Figure 1A). However, in TMS 98/0581 and MS-3, MS reduced number of leaves by more than $50 \%$ and ES lead to complete loss of leaves on the plantlets. About $50 \%$ reduction in number of leaves

were observed when explants of TME 419 and TMS 97/2205 were subjected to MS and ES. Reduction in NL under drought and P stresses might be for the purpose of decreasing transpiration and adjustment of photosynthetic machinery, as leaves are the organs that contain chloroplasts and stomata, which are associated with photosynthesis and transpiration, respectively. According to 
Roitsch [17], when water supply is significantly decreased, plants adjust growth, leaf formation and photosynthetic activities, which affect carbon partitioning between tissues that serve as sink and source. As a result, sugars that are utilized for normal plant growth are redirected to selective growth of roots and shoots or towards production of osmoprotectants [18]. Previous laboratory and field studies have identified stomata closure, reduction in leaf size and number and restriction in rate of new leaf appearance as some of the stress-avoidance mechanisms employed by cassava to ensure conservative use of water to sustain photosynthesis during water-deficit stress $[19,20]$. Recently, NL of TMS 84/00353, MM 96/1751 and MM 98/3437 was reported insensitive to mannitol treatment by Jolayemi \& Opabode [15].

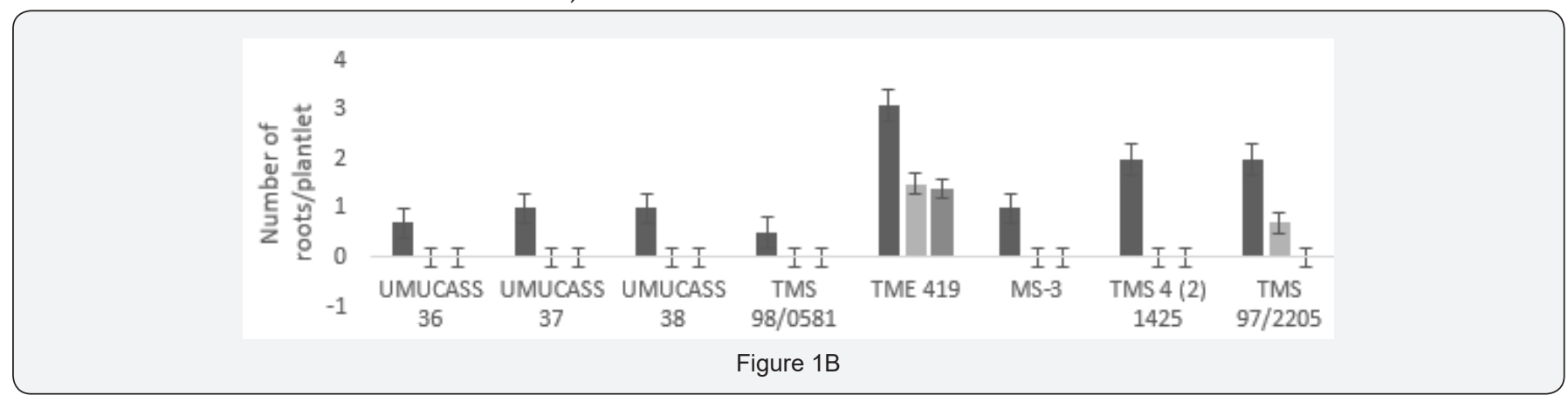

All cultivars produced roots in CT medium with the highest number of roots produced by TME 419 (Figure1B). Cultivars UMUCASS 36, UMUCASS 37, UMUCASS 38, TMS 98/0581, MS-3, TMS 4(2) 1425 did not develop root on MS and ES media. MS and ES media reduced number of root by 60 and $63 \%$, respectively in TME 419. In TMS 97/2205, MS reduced number of root by $70 \%$ while ES lead total reduction in root formation. Cassava fibrous root system consists of adventitious and lateral roots.

Experiments have shown that production (formation) and growth (elongation) of cassava's adventitious and lateral roots are suppressed by deficit in soil moisture [5,6]. Root formation and elongation are difficult processes to achieve by explants under stress which informed inability of $75 \%$ of the cultivars to produce root under stress. However, TME 419 and TMS 97/2205 produced roots, suggesting the two cultivars are tolerant of drought and $\mathrm{P}$ stresses [21].

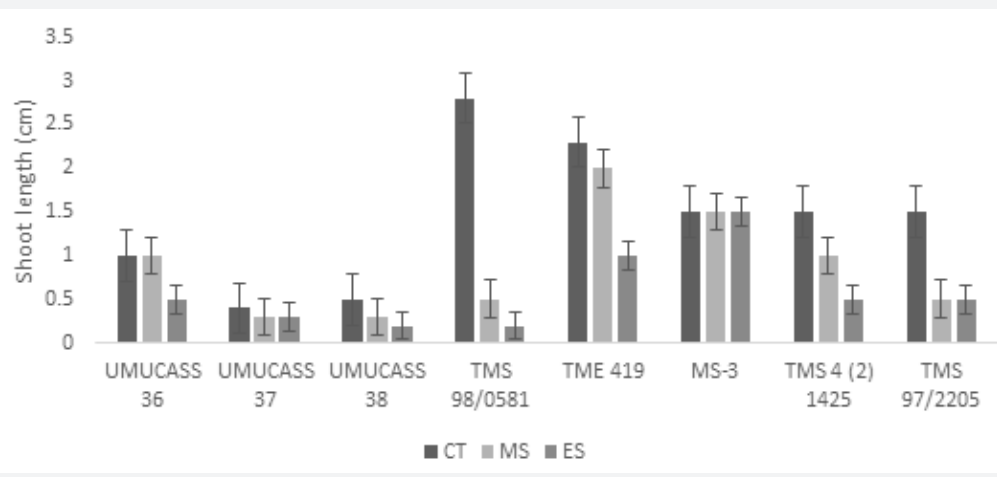

Figure 1C

Figure 1: Interaction of cultivar and stress medium on number of leaves, number of roots and shoot length.

Shoot length was reduced by an average of 5 and $12 \%$ on MS and ES media, respectively in UMUCASS 36, UMUCASS 37 , UMUCASS 38, TME 419, and TMS 4(2) 1425 (Figure 1C). In TMS 98/0581 and TMS 97/2205, reduction of shoot length was greater than half on both MS and ES media whereas MS-3 showed no reduction in shoot length in both MS and ES media. Cessation of shoot growth is one of the first responses of plants subjected to drought stress $[22,23]$. Reduction in shoot growth under moisture stress has some benefits, i.e., reduced metabolic activity in and energy consumption by plant and re-direction of metabolites to the production of materials required for osmotic adjustment [23].

\section{Conclusion}

All cultivars developed shoots, roots, leaves and apical meristem from nodal segment explants on control medium while $25 \%$ of the cultivars developed those organs on moderate water and P stress (MS) medium. Only TME 419 developed roots, shoots, leaves and apical meristem on extreme water and P stress (ES) medium while MS-3 produced no organs on ES medium. Our results suggested that in vitro screening is feasible for identification of drought and $\mathrm{P}$ deficit tolerant cassava varieties. In addition, our data suggested that TME 419 is tolerant of drought and P deficit stresses and strongly recommended for farmers.

\section{Acknowledgement}

The authors appreciate an offer of Research Fellowship given to the first author by the National Center for Genetic Resources and Biotechnology (NACGRAB), Moor Plantation, Ibadan, Nigeria. 


\section{References}

1. Okogbenin E1, Setter TL, Ferguson M, Mutegi R, Ceballos H, et al. (2013) Phenotypic approaches to drought in cassava. Front Physiol 4: 93.

2. Turyagyenda FL, Kizito BE, Yona B, Osiru D (2013) Evaluation of Uganda cassava germplasm for drought tolerance. International Journal of Agriculture and Crop Sciences 5: 212-226.

3. Igberi CO, Awoke MU (2013) Cassava production and gender factor challenges affecting cassava production in Ebonyi state, Nigeria. Journal of Agriculture and Veterinary Sciences 2(5): 21-24.

4. (2007) Climate change. The physical science basis. In: Contribution of Working Group I to the Fourth Assessment Report of the Intergovernmental Panel on Climate Change. Cambridge University Press, Cambridge, UK, p. 1-10.

5. Bergantin RV, Yamauchi A, Pardales JR, Bolatete-Al DM (2004) Screening cassava genotypes for resistance to water deficit during crop establishment. Philippines Journal of Crop Science 29(1): 29-39.

6. Aina O0, Dixon AG, Akinrinde EA (2007) Effect of Soil Moisture Stress on Growth and Yield of Cassava in Nigeria. Pak J Biol Sci 10(18): 30853090 .

7. El-Sharkawy MA, Cadavid LF (2002) Response of Cassava to prolonged water stress imposed at different stages of growth. Experimental Agriculture 38: 333-350.

8. Vandegeer R, Miller RE, Bain M, Gleadow RM, Cavagnaro TR (2013) Drought adversely affects tuber development and nutritional quality of the staple crop cassava (Manihot esculenta Crantz). Functional Plant Biology 40(2): 195-200.

9. Busman L, Lamb J, Randall G, Rehm G, Schmitt M (2009) The nature of Phosphorus in Soils. Regents of the University of Minnesota, USA, p. 87-98.

10. Sarker BC, Karmoker JL (2011) Effects of Phosphorus Deficiency on accumulation of Biochemical Compounds in Lentil (Lens culinaris Medik). Bangladesh Journal Botany 40(1): 23-27.

11. Didier P, Mabrouk AE (1993) Cassava varietal response to phosphorus fertilization. II. Yield, biomass and gas exchange. Field Crops Research 35(1): 13-20.

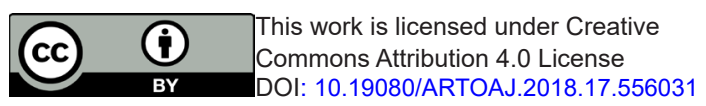

12. Murashige T, Skoog F (1962) A revised medium for rapid growth and bioassays with tobacco tissue cultures. Physiologia Plantarium 15(3): 473-497.

13. (2002) SAS/STAT Users Guide. Version 6, (4 $4^{\text {th }}$ edn), Vol 1, Cary, NC: SAS Institute Inc. SAS publication, USA, pp. 5136.

14. Opabode JT (2010) Development of Transgenic cassava plants with potentials for starch modification. Ph.D Thesis. Obafemi Awolowo University, Nigeria, pp. 178.

15. Jolayemi OL, Opabode JT (2018) Response of cassava to in vitro induced-mannitol drought stress. Journal of Crop Improvement 32(4): 566-578.

16. Opabode JT, Akinyemiju OA (2017) Somatic embryogenesis and regeneration of five multipurpose cassava landrace extensively integrated in African cropping system. Journal of Crop Improvement 31(1): 56-71.

17. Roitsch T (1999) Source-sink regulation by sugar and stress. Curr Opin Plant Biol 2(3): 198-206.

18. Lei Y, Yin C, Li C (2006) Differences in some morphological, physiological and biochemical responses to drought stress in two contrasting populations of Populus przewalskii. Physiologia Plantarium 127(2): 182-191.

19. El-Sharkawy MA (2004) Cassava Biology and Physiology. Plant Mol Biol 56(4): 481-501.

20. El-Sharkawy MA (2012) Stress-tolerant cassava: the role of integrative ecophysiology-breeding research in crop improvement. Open Journal of Soil Science 2(2): 162-186.

21. Hsaio TC, Xu LK (2000) Sensitivity of growth of roots versus leaves to water stress: biophysical analysis and relation to water transport. Journal Experimental Botany 51(350): 1596-1616.

22. Pardales JR, Yamauchi A, Belmonte DV, Esquibel CB (2001) Dynamics of root development in root crops in relation to the prevailing moisture stress in the soil. Proceedings of the 6th symposium of the International Society of Root Research, Nagoya, Japan, pp. 72-73.

23. Bhargava S, Sawant KS (2013) Drought stress adaptation: metabolic adjustment and regulation of gene expression. Plant Breeding 132(1): 21-32.

Your next submission with Juniper Publishers
will reach you the below assets
- Quality Editorial service
- Swift Peer Review
- Reprints availability
- E-prints Service
- Manuscript Podcast for convenient understanding
- Global attainment for your research
- Manuscript accessibility in different formats
( Pdf, E-pub, Full Text, Audio)
- Unceasing customer service
Track the below URL for one-step submission
https://juniperpublishers.com/online-submission.php

